\title{
Evaluation of the effect of EDTA on root coverage at free gingival graft procedure
}

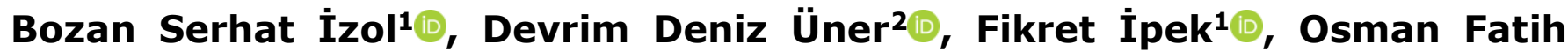 Arpağ3 3}

${ }^{1}$ Dicle University, Faculty of Dentistry, Department of Periodontology, Diyarbakır, Turkey

2 Harran University, Faculty of Dentistry, Department of Periodontology, Şanlıurfa, Turkey

${ }^{3}$ Mustafa Kemal University, Faculty of Dentistry, Department of Periodontology, Hatay, Turkey

\section{Correspondence:}

Dr. Devrim Deniz ÜNER

Harran University, Faculty of Dentistry,

Department of Periodontology,

Şanlıurfa, TURKEY.

E-mail:dvrmdnznr@gmail.com

Received: 27 February 2018

Accepted: 25 March 2018

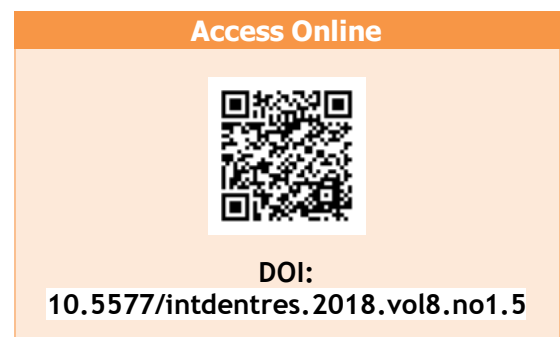

\section{Abstract}

Aim: The present study was designed to compare the effect of root surface biomodification with ethylenediaminetetraacetic acid (EDTA) for the treatment of buccal gingival recession using the free gingival graft (FGG) technique.

Methodology: In this randomized controlled parallel clinical trial, 34 patients with 40 teeth with Miller Class I and Class II gingival recessions were treated using FGG. The 40 teeth with recessions were assigned randomly to receive FGG with or without the application of EDTA gel. On pre-treatment (Day 0) and at 3-months and 6-months post-treatment, the following parameters were measured: gingival recession height $(\mathrm{GRH})$, gingival recession width (GRW), probing pocket depth (PD), clinical attachment level (CAL), and width of keratinized tissue (WKT).

Results: In the FGG+EDTA group, statistically significant changes from baseline were found: $G R H$ decreased from $4.7 \pm 1.5 \mathrm{~mm}$ to $1.3 \pm 1.2$ and WKT increased from $0.9 \pm 0.9 \mathrm{~mm}$ to $5.5 \pm 1.8 \mathrm{~mm}$. In the FGG group, GRH decreased from $4.6 \pm 1.3 \mathrm{~mm}$ to $1.3 \pm 1.2 \mathrm{~mm}$ and WKT increased from $0.9 \pm 0.7 \mathrm{~mm}$ to $5.4 \pm 1.5 \mathrm{~mm}$. For the FGG and FGG+EDTA groups, average root coverage was found to be $74.14 \%$ and $69.26 \%$, respectively.

Conclusions: The data demonstrated that the root surface biomodification agent, EDTA, had no beneficial effect on root coverage.

Keywords: Gingival recession, free gingival graft, ethylenediaminetetraacetic acid, root coverage

How to cite this article: İzol BS, Üner DD, İpek F, Arpağ OF. Evaluation of the effect of EDTA on root coverage at free gingival graft procedure. Int Dent Res 2018;8(1):2834. 


\section{Introduction}

The tissues that support the teeth are called the periodontium; this consists of the gingiva, the periodontal ligament, the cementum, and alveolar bone (1). Gingival recession is the term used to characterize the apical shift of the marginal gingiva from its normal position on the crown of the tooth to the levels on the root surface beyond the cementoenamel junction (2). Gingival recession may have various etiologies, including faulty tooth brushing methods, tooth malposition, friction from soft tissue, abnormal frenum attachment, and iatrogenic dentistry (3). Moreover, gingival inflammation, such as periodontitis, destroys the structures of the periodontium and causes gingival recession (4). When gingival recession occurs, patients are concerned about three main factors: poor aesthetics, potential tooth loss, and dentin hypersensitivity (5). Several surgical procedures, such as pedicle flaps, free soft tissue grafts, and combinations of pedicle flaps and grafts or barrier membranes, have been found to improve the coronal level of the gingival margin on the root surface (6). Among these surgical procedures, free gingival graft $(F G G)$ is one of the most common techniques used for gingival augmentation.

FGG helps enhanced plaque removal around the gingival margin, reduces gingival inflammation, and improves aesthetics (7). FGG was first described by Bjorn in 1963 (8). Since then, FGG has been used to cover denuded root surfaces and to increase the width and thickness of the attached gingiva. FGG is advantageous due to it high predictability and relative ease of use. However, conventional FGG has several inherent limitations, such as aesthetic mismatch and a bulky appearance (9). Complete root coverage is the ultimate goal of FGG, and attempts have been made to increase the success rate and predictability of various FGG methods (6). Alterations in the pathologicallyexposed root surfaces can inhibit the formation of new connective tissue (10). Therefore, several modification agents have been used at different concentrations and time intervals to selectively modify the contaminated root surface by exposing collagen fibers and by creating a hospitable substrate that favors the migration and attachment of fibroblasts (11). Root surface biomodification (RSB) agents, such as citric acid or tetracycline hydrochloride, have been advocated to promote the healing response following root surface coverage, although clinical studies have failed to show any improvement in root surface coverage when using those agents $(12,13)$. Bittencourt et al. reported that the use of ethylenediaminetetraacetic acid (EDTA) gel as an RSB agent negatively affected the outcome of root coverage with the semilunar coronally repositioned flap (14). The present study aimed to compare the effect of RSB with EDTA for the treatment of buccal gingival recession with FGG.

\section{Materials and Methods}

A total of 34 patients (10 males and 24 females), who were complaining of Miller Class I and Class II gingival recession, were included in this prospective clinical study. The patients that were selected for periodontal surgical treatment had no contraindications and no systemic disease that would affect wound healing The patients' smoking habits were not considered. It was noted that the patients had Miller Class I and Class II gingival recessions, no interdental bone and soft tissue loss, and a pocket depth (PD) that was not less than $3 \mathrm{~mm}$ in the recession area. Moreover, only the lower jaw incisors and the first premolar gingival recessions were included in the study. The patients involved in the study were informed about the clinical trial, and their verbal approval to participate was obtained. These 34 patients had 40 gingival recessions in their teeth. Forty teeth were selected randomly, and the patients were placed into two groups (FGG group, and FGG+EDTA group).

The selected patients were informed about oral hygiene management. The plaque index $(\mathrm{PI})$, gingival index $(\mathrm{Gl})$, and PDs of the patients were measured. After the measurements were obtained, scaling and root planing operations were performed in the required areas. During this process, there was no interference with the root surface. Patients were considered to have $\mathrm{PI}$ and $\mathrm{Gl}$ scores close to zero before surgery. The gingival recession height (GRH), gingival recession width (GRW), clinical attachment level (CAL), PD, and the width of the keratinized tissue (WKT) of the patients who had suitable oral hygiene were measured before the surgical procedure was undertaken.

Toward that end, $10 \%$ povidone-iodine was prepared, and the solution was applied to the gingival and alveolar mucosa with cotton pellets to more clearly determine the mucogingival line when measuring WKT. All measurements were taken using a Williams periodontal probe (Hu-Friedy $\circledast$, Chicago, IL, USA), and the measures were completed to the nearest millimeter. Plates were prepared from orthodontic acrylic by taking measurements from the upper jaws of the patients before the surgical procedure. These plates were applied to the patients after surgery. All the measurements were recorded on the forms, and initial clinical pictures were taken for each patient. In 
the FGG+EDTA group 24\% EDTA (Fig. 1) was applied as an RSB agent; in the control FGG group, no agent was applied to the root surface.

At 3-and 6-months postoperatively, all the clinical measurements were repeated, and clinical photographs of the patients were obtained (Fig. 2).

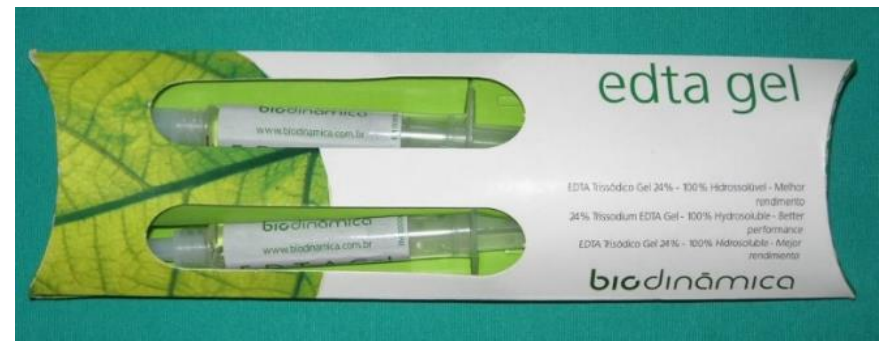

Figure 1. EDTA gel 24\%
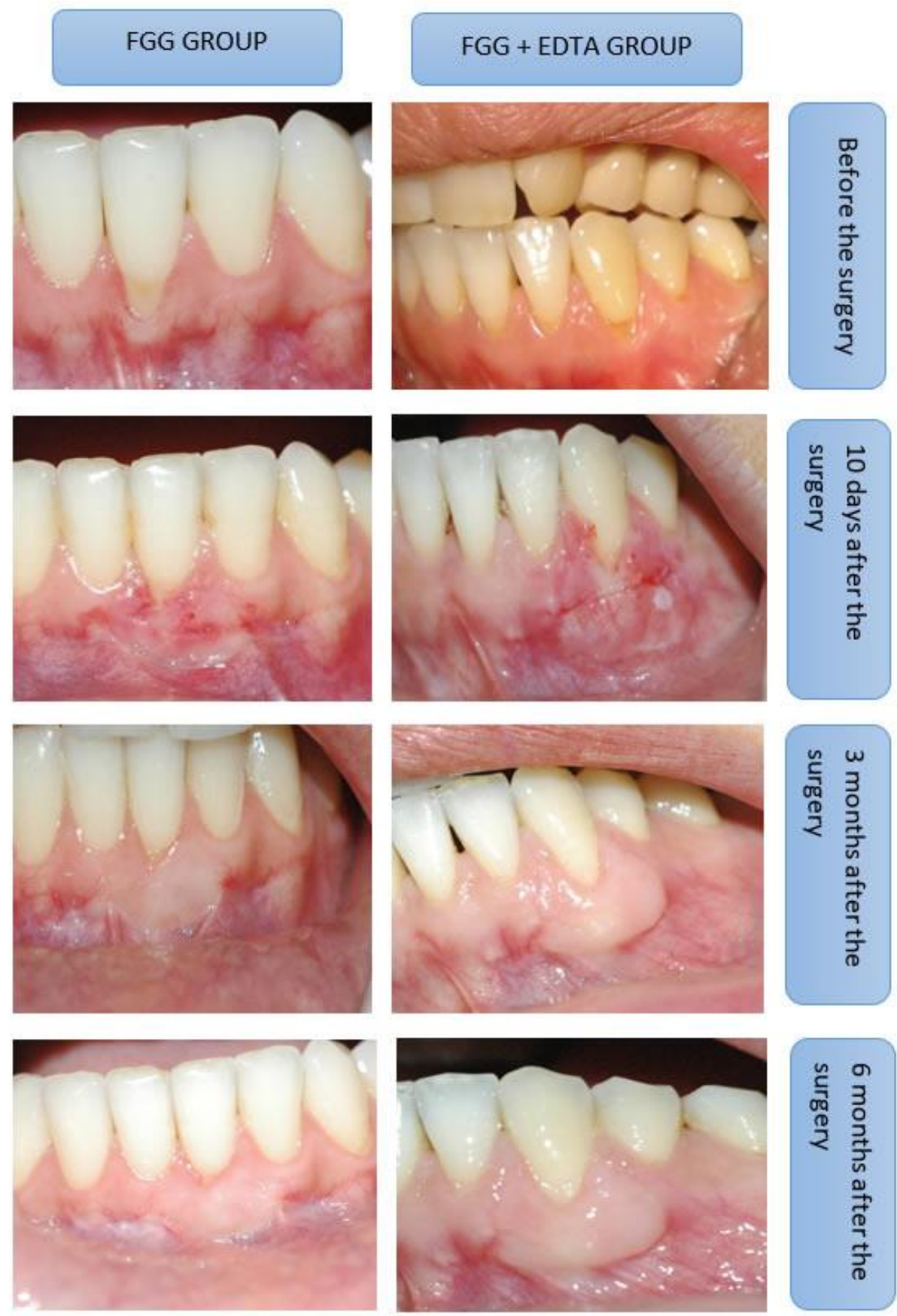

Figure 2. Images obtained from patients for the two groups from preoperative to postoperative. 


\section{Statistical Analysis}

The measurements obtained from the patients were analyzed using SPSS 20 software. The dental data for each of the patients were analyzed. Descriptive statistical methods were applied to determine frequency, percentage, mean, and standard deviation. The GRH measurements were obtained in the initial examination and in the two follow-up periods, the GRW, the CAL, and the WKT measurements were reported as mean \pm standard deviation. The independent samples t-test was used for normal distribution of the variables and the Mann-Whitney-U test was used for non-normal distributions. The Wilcoxon Signed Rank test was used to analyze the intra-group data. The results were accepted as $95 \%$ confidence interval, and $p<0.05$ was considered to be statistically significant

\section{Results}

In this study, $70.5 \%$ of the patients were female and $29.5 \%$ were male. The patients ranged in age from 12 to 54 , and the mean age was 29.6. The average age of the female patients participating in the study was 28.62, and the average age of the males was 32.3. The following types of teeth were included in this study: mandibular-incisors (65\%), canines (22.5\%), and maxillary lateral incisors (12.5\%). Four of the patients had aesthetic problems, 22 had dentin hypersensitivity problems due to exposure of their root surfaces, and the remaining 8 were referred to our clinic for complaints of both aesthetic and dentine hypersensitivity.

The $\mathrm{PI}, \mathrm{GI}$, and $\mathrm{PD}$ values and the standard deviations between the patient groups (FGG+EDTA group and the FGG group) and between the groups after 6 months from surgery are shown in Table 1. A statistically significant decrease of $\mathrm{PI}, \mathrm{GI}$ and $\mathrm{PD}$ was observed in the FGG group after surgery in comparison to the values before surgery, whereas a statistically significant reduction in PI and PD was found in the FGG+EDTA group and a statistically significant decrease in the GI was found in the FGG group. No statistically significant difference was observed in $\mathrm{PI}, \mathrm{Gl}$, and PD values prior to surgery and 6 -months after surgery for both groups.

A comparison of the FGG+EDTA group prior to surgery and 3 months after surgery showed that there was a statistically significant decrease in GRH and CAL and a statistically significant decrease in GRW. However, at the end of the third month, a statistically significant increase was found in WKT. The probing pocket depth (PD) was not statistically different. When the prior to surgery and the 6-month values were compared for the same group, a significant decrease was found in the GRH and PD values, a significant decrease was found in the GRW values, and a statistically significant increase was found in the WKT. The differences in the PD values were not statistically significant. There was no statistically significant difference in any of the values 3- and 6-months, postoperatively (Table 2 ). In our study, the mean of root surface coverage was $74.14 \%$ in the FGG group and $69.26 \%$ in the FGG+EDTA group. Complete root surface coverage was achieved in $35 \%$ of the teeth in the FGG group and in $30 \%$ of the teeth in the FGG+EDTA group. In the FGG + EDTA group, a complete root surface coverage was obtained in 4 teeth $(20 \%)$ at $3 r d$ month after surgery, and this value advanced to $6(35 \%)$ at the end of 6 months after surgery. On the other hand, in the FGG group, a complete root surface coverage was obtained at three teeth at three months, but this coverage amount reached 7 (35\%) at six months after surgery (Table 3 ). The causes of the increase of root surface coverage amount with time are related to creeping attachment. The creeping attachment is postoperative migration of the gingival marginal tissue in coronal direction.

Table 1. Pre- and post-operative clinical parameters of the test and control groups

$\begin{array}{clccc} & & \begin{array}{r}\text { Test Group } \\ (F G G+E D T A)\end{array} & \begin{array}{r}\text { Control Group (FGG) } \\ \text { Between Test and } \\ \text { Control Groups (p) }\end{array} \\ \text { PI } & \text { b } & 0.5 \pm 0.4 & 0.5 \pm 0.4 & \text { NS } \\ & \text { m6 } & 0.3 \pm 0.1 & 0.2 \pm 0.2 & \text { NS } \\ \text { GI } & \text { b } & 0.4 \pm 0.2 & 0.3 \pm 0.2 & \text { NS } \\ & \text { m6 } & 0.1 \pm 0.1 & 0.1 \pm 0.2 & \text { NS } \\ \text { PD } & \text { m6 } & 1.4 \pm 0.1 & 1.3 \pm 0.2 & \text { NS } \\ \end{array}$

b: Pre-operative and m6: 6 months after surgery) Statistically significant: $p<0.05$. NS: Not significant. 
Table 2. Clinical parameters of the FGG + EDTA and FGG group before treatment, at three months and the end of 6 months.

\begin{tabular}{|c|c|c|c|}
\hline & $\begin{array}{c}\text { FGG + EDTA } \\
\text { (6. month) }\end{array}$ & $\begin{array}{c}\text { FGG } \\
\text { (6.month) }\end{array}$ & $\mathbf{p}^{*}$ \\
\hline GRH (mm) & $1.3 \pm 1.2$ & $1.3 \pm 1.2$ & 0.862 \\
\hline GRW (mm) & $1.6 \pm 1.3$ & $1.5 \pm 1.3$ & 0.862 \\
\hline KGW (mm) & $5.5 \pm 1.8$ & $5.4 \pm 1.5$ & 0.989 \\
\hline PD (mm) & $1.0 \pm 0.2$ & $1.0 \pm 0.2$ & 0.100 \\
\hline CAL $(\mathrm{mm})$ & $2.3 \pm 1.2$ & $2.4 \pm 1.2$ & 0.947 \\
\hline
\end{tabular}

GRH: Gingival recession height, GRW: Gingival recessesion width, KGW: Keratinized gingival width, PD: Probing pocket depth, CAL: Clinical atachment level, Mean, SD: Standart Deviation, $\mathrm{p}<0.05$

Table 3. The amount of root coverage, the number and percentage of teeth with complete root coverage at in both groups (FGG and FGG + EDTA groups).

\begin{tabular}{|c|c|c|c|c|c|c|}
\hline & $\mathbf{n}$ & $\%$ of root coverage & $\begin{array}{l}\text { Complete } \\
\text { root } \\
\text { coverage }\end{array}$ & $\begin{array}{l}\text { Complete } \\
\text { root coverage }\end{array}$ & $\begin{array}{l}\text { Number of } \\
\text { teeth } \\
\text { observed } \\
\text { complete root } \\
\text { coverage }\end{array}$ & $\begin{array}{l}\text { Number of } \\
\text { teeth } \\
\text { observed } \\
\text { complete } \\
\text { root } \\
\text { coverage }\end{array}$ \\
\hline Month & & 6. months & 3. months & 6. months & 3. months & 6. months \\
\hline FGG & 20 & $\% 74.14 \pm 22.99$ & $\% 15$ & $\% 35$ & 3 & 7 \\
\hline $\begin{array}{l}\text { FGG + } \\
\text { EDTA }\end{array}$ & 20 & $\% 69.26 \pm 26.28$ & $\% 20$ & $\% 30$ & 4 & 6 \\
\hline Total & 40 & & & & 7 & 13 \\
\hline
\end{tabular}

\section{Discussion}

Gingival recession is the result of gingival margin migration from the cementoenamel junction towards the apical, leaving the root surface exposed and leading to aesthetic problems, dentin sensitivity, and areas that are difficult to access for oral hygiene (15). Many methods have been used to treat gingival recessions. A successful root surface closure procedure depends on many factors, such as the patient's anatomical configuration, the surgeon's surgical skills, and the patient's postoperative care. Complete root coverage can be obtained by using subepithelial connective tissue graft (SCTG) to treat Miller Class I and Class II gingival recessions, and this has been accepted as the gold standard. Complete root coverage is the ultimate goal of the FGG technique (16). The success or failure of FGG depends on many factors, including inadequate blood supply in the graft bed, the interproximal tissue level, and whether or not the incision is sufficient for the blood to successfully penetrate the graft on the root surface. Grafting might not be well-adapted to the bed, and interdental bone loss can impede the ability to ensure complete root surface covering (17). Some researchers have noted that RSB with chemical agents, associated with scaling and root planing, develops gingival attachment (10). Studies have shown that application of $18 \%$ EDTA on the root surface facilitates development of fibroblast attachment and migration on the root surface (18). In contrast, other studies in which 24\% EDTA was applied to root surfaces have shown that this had no effect on PD, CAL, and the PPD levels between all groups (19). The negative or positive effects of EDTA as an RSB agent applied to the root surface before periodontal surgery is still a debated issue. Therefore, we used EDTA as an RSB agent in addition to scaling and root planing in order to enhance the success of surgery and increase the root surface closure.

Numerous studies have been done with various techniques, such as lateral positional flaps, coronally repositioned flaps, double papilla flaps, semilunar flaps, connective tissue grafts, and FGG to cover the root surface (20-24). FGG was first detailed in a study by Sullivan and Atkins in which it was used to cover gingival defects (25). Complete root coverage is considered the true goal of treatment because it ensures recovery from the hypersensitivity and 
aesthetic defects associated with recession areas (6, 21). Many studies have investigated the application of FGGswith the aim of covering open root surfaces. In 1990, Daniel and Cheru compared FGG and subepithelial connective tissue graft (SCTG) techniques in the treatment of localized gingival recessions; they reported obtaining an average $49.8 \%$ root surface coverage with FGG (24). Paolantonio et al. compared the use of FGG and SCTG for root surface coverage; they reported that the mean of root coverage in patients in the FGG group was $53.19 \%$ and the complete resolution of gingival recession after treatment was $8.75 \%$ in the FGG group (26). In our study, the mean of root surface coverage was $74.14 \%$ in the FGG group and $69.26 \%$ in the FGG+EDTA group. Complete root surface coverage was achieved in $35 \%$ of the teeth in the FGG group and in $30 \%$ of the teeth in the FGG+EDTA group.

Several studies have been done to improve the percentages of complete coverage with RSB (27-29). A study conducted in 1988 by Bertrand et al. showed that citric acid used as a root surface modification agent did have a statistically significant impact on the surgical root coverage results (23). Studies carried out using different root modification agents and various surgical methods have shown that RSB agents have not had a positive impact on the surgical root coverage results, and those agents even have an adverse effect $(14,30-$ 36). In a meta-analysis, Oliveria et al. showed that RSB agents do not affect the outcomes of surgical root coverage operations (37). Furthermore, a systematic review documented that RSB agents do not affect the outcomes of surgical root coverage procedures (6). This outcome may be related to the formation and development of clots. Blood clots have a negative impact on sensitive surgery methods, such as periodontal surgery, because anticoagulant materials, such as EDTA, delay the healing by causing a blood clot to move away from the root surface (14). In the present study, a significant reduction in GRH was observed. Even though recession reduction was seen in both groups, better coverage was seen in the FGG group.

\section{Conclusions}

In this study, localized gingival recession was treated with FGG, using 24\% EDTA as an RSB agent; however, the use of EDTA did not have any statistically significant effect. In this study, the mean of the root coverage in the patients in the FGG group was $74.14 \%$ while the mean of the root coverage in the FGG+EDTA group was $69.26 \%$. Based on this result, we conclude that EDTA has not a positive or negative effect on the ability to cover the root surfaces.
Ethical Approval: Ethics committee approval was received for this study from Dicle University, Faculty of Dentistry (Decision Date: May 12, 2009; Decision Number: 2009/23).

Informed Consent: Written informed consent was obtained from all the patients who participated in this study.

Peer-review: Externally peer-reviewed.

Author Contributions: Conception - B.S.I.; Design - B.S.I., D.D.Ü.; Supervision - F.I.; Materials - D.D.Ü.; Data Collection and/or Processing - F.i., O.F.A.; Analysis and/or Interpretation - B.S.I., F.i.; Literature Review - Fi.,, O.F.A.; Writer- B.S.I., D.D.Ü.; Critical Review - D.D.Ü., O.F.A.

Conflict of Interest: No conflict of interest was declared by the authors.

Financial Disclosure: This study was supported by Dicle University Scientific Research Projects Coordination Unit. Project Number: 09DH-029, 2009, Turkey)

\section{References}

1. Velden U. Effect of age on the periodontium. Journal of clinical periodontology. 1984;11(5):281-94. [Crossref]

2. Loe $\mathrm{H}$, Anerud A, Boysen $\mathrm{H}$. The natural history of periodontal disease in man: prevalence, severity, and extent of gingival recession. Journal of periodontology. 1992;63(6):489-95. [Crossref]

3. Carranza FA, Camargo P. The periodontal pocket. Clinical Periodontology, 10th ed Philadelphia: Saunders/Elsevier. 2006:434-51.

4. Williams RC. Periodontal disease. The New England journal of medicine. 1990;322(6):373-82. [Crossref]

5. Zalkind $M$, Hochman N. Alternative method of conservative esthetic treatment for gingival recession. Journal of Prosthetic Dentistry. 1997;77(6):561-3. [Crossref]

6. Roccuzzo M, Bunino M, Needleman I, Sanz M. Periodontal plastic surgery for treatment of localized gingival recessions: a systematic review. J Clin Periodontol. 2002;29 Suppl 3:178-94; discussion 95-6. [Crossref]

7. Sangnes G, Gjermo P. Prevalence of oral soft and hard tissue lesions related to mechanical toothcleansing procedures. Community Dentistry and Oral Epidemiology. 1976;4(2):77-83. [Crossref]

8. Bjorn H. Free transplantation of gingival propria. Sven Tandlak Tidskr. 1968;22:684-9.

9. Cohen ES. Atlas of cosmetic and reconstructive periodontal surgery. 2 ed: PMPH-USA; 2007.

10. Polson A, Proye M. Effect of root surface alterations on periodontal healing. Journal of Clinical Periodontology. 1982;9(6):441-54. [Crossref]

11. Zaman KU, Sugaya T, Hongo $O$, Kato H. A study of attached and oriented human periodontal ligament cells to periodontally diseased cementum and dentin after demineralizing with neutral and low $\mathrm{pH}$ etching solution. Journal of periodontology. 2000;71(7):1094-9. [Crossref]

12. Zucchelli G, Mounssif I, Stefanini M, Mele M, Montebugnoli L, Sforza N. Hand and Ultrasonic Instrumentation in Combination With Root-Coverage Surgery: A Comparative Controlled Randomized Clinical Trial. Journal of periodontology. 2009;80(4):577-85. [Crossref]

13. Mariotti A. Efficacy of chemical root surface modifiers in the treatment of periodontal disease. A systematic review. Annals of periodontology. 2003;8(1):205-26. [Crossref] 
14. Bittencourt $S$, Ribeiro Edel P, Sallum EA, Sallum AW, Nociti FH, Jr., Casati MZ. Root surface biomodification with EDTA for the treatment of gingival recession with a semilunar coronally repositioned flap. Journal of periodontology. 2007;78(9):1695701. [Crossref]

15. Carranza FA, Jr., Carraro JJ. Mucogingival techniques in periodontal surgery. Journal of periodontology. 1970;41(5):294-9. [Crossref]

16. Cairo F, Pagliaro U, Nieri M. Treatment of gingival recession with coronally advanced flap procedures: a systematic review. Journal of clinical periodontology. 2008;35(s8):136-62. [Crossref]

17. Miller Jr P. A classification of marginal tissue recession. Int $\mathrm{J}$ Periodontics Restorative Dent. 1985;5:8-13.

18. Pitaru S, Melcher AH. Organization of an oriented fiber system in vitro by human gingival fibroblasts attached to dental tissue: relationship between cells and mineralized and demineralized tissue. Journal of periodontal research. 1987;22(1):6-13. [Crossref]

19. Blomlof L, Jonsson B, Blomlof J, Lindskog S. A clinical study of root surface conditioning with an EDTA gel. II. Surgical periodontal treatment. The International journal of periodontics \& restorative dentistry. 2000;20(6):566-73.

20. Gürgan CA, Oruç AM, Akkaya M. Alterations in location of the mucogingival junction 5 years after coronally repositioned flap surgery. Journal of periodontology. 2004;75(6):893-901. [Crossref]

21. Chambrone L, Chambrone D, Pustiglioni FE, Chambrone LA, Lima LA. Can subepithelial connective tissue grafts be considered the gold standard procedure in the treatment of Miller Class I and II recession-type defects? Journal of dentistry. 2008;36(9):659-71. [Crossref]

22. Cortellini P, Pini Prato G. Coronally advanced flap and combination therapy for root coverage. Clinical strategies based on scientific evidence and clinical experience. Periodontology 2000. 2012;59(1):158-84. [Crossref]

23. Bertrand PM, Dunlap RM. Coverage of deep, wide gingival clefts with free gingival autografts: root planing with and without citric acid demineralization. The International journal of periodontics \& restorative dentistry. 1988;8(1):64-77.

24. Daniel A, Cheru R. Treatment of localised gingival recession with subpedicle connective tissue graft and free gingival auto graft--a comparative clinical evaluation. Journal of the Indian Dental Association. 1990;61(12):294-7.

25. Sullivan HC, Atkins JH. Free autogenous gingival grafts. 3. Utilization of grafts in the treatment of gingival recession. Periodontics. 1968;6(4):152-60.

26. Paolantonio $M$, di Murro C, Cattabriga A, Cattabriga $M$. Subpedicle connective tissue graft versus free gingival graft in the coverage of exposed root surfaces. A 5-year clinical study. J Clin Periodontol. 1997;24(1):51-6. [Crossref]

27. Oles R, Ibbott C, Laverty W. Effects of citric acid treatment on pedicle flap coverage of localized recession. Journal of periodontology. 1985;56(5):259-61. [Crossref]

28. Trombelli L, Schincaglia GP, Zangari F, Griselli A, Scabbia A, Calura G. Effects of tetracycline $\mathrm{HCl}$ conditioning and fibrinfibronectin system application in the treatment of buccal gingival recession with guided tissue regeneration. Journal of periodontology. 1995;66(5):313-20. [Crossref]

29. Bouchard $P$, Nilveus $R$, Etienne D. Clinical evaluation of tetracycline $\mathrm{HCl}$ conditioning in the treatment of gingival recessions. A comparative study. Journal of periodontology. 1997;68(3):262-9. [Crossref]

30. Caffesse RG, LaRosa MD, Garza M, Munne-Travers A, Mondragon JC, Weltman R. Citric acid demineralization and subepithelial connective tissue grafts. Journal of periodontology. 2000;71(4):568-72. [Crossref]
31. Kassab MM, Cohen RE, Andreana S, Dentino AR. The effect of EDTA in attachment gain and root coverage. Compendium of continuing education in dentistry (Jamesburg, NJ: 1995). 2006;27(6):353-60; quiz 61.

32. Dilsiz A, Aydin T, Canakci V, Cicek Y. Root surface biomodification with Nd: YAG laser for the treatment of gingival recession with subepithelial connective tissue grafts. Photomedicine and laser surgery. 2010;28(3):337-43. [Crossref]

33. Dilsiz A, Aydin T, Yavuz MS. Root surface biomodification with an Er: YAG laser for the treatment of gingival recession with subepithelial connective tissue grafts. Photomedicine and laser surgery. 2010;28(4):511-7. [Crossref]

34. Andrade PF, Grisi MF, Marcaccini AM, Fernandes PG, Reino DM, Souza SL, et al. Comparison Between Micro-and Macrosurgical Techniques for the Treatment of Localized Gingival Recessions Using Coronally Positioned Flaps and Enamel Matrix Derivative. Journal of periodontology. 2010;81(11):1572-9. [Crossref]

35. Hagewald S, Spahr A, Rompola E, Haller B, Heijl L, Bernimoulin JP. Comparative study of Emdogain and coronally advanced flap technique in the treatment of human gingival recessions. A prospective controlled clinical study. J Clin Periodontol. 2002;29(1):35-41. [Crossref]

36. Buggapati L, Chava VK. Effect of combination of ethylenediaminetetraacetic acid+ tetracycline with coronally positioned flap in the treatment of gingival recession: A clinical study. Journal of Indian Society of Periodontology. 2016;20(1):57-62. [Crossref]

37. Oliveira G, Muncinelli E. Efficacy of root surface biomodification in root coverage: a systematic review. J Can Dent Assoc. 2012;78:c122. 